\title{
Estrogen metabolism by the equine embryo proper during the fourth week of pregnancy
}

\author{
James I Raeside, Heather L Christie, Rudolf O Waelchli and Keith J Betteridge \\ Department of Biomedical Sciences, University of Guelph, Guelph, Ontario, Canada N1G2W1 \\ Correspondence should be addressed to J I Raeside; Email: jraeside@uoguelph.ca
}

\begin{abstract}
Estrogen production by the trophoblast is considered important in early equine pregnancy and leads to high concentrations in yolk-sac (Y-S) fluid. The embryo proper is a potential site for their action. We examined estrogen metabolism in the embryo proper because some actions of estrogens are derived from locally formed metabolites. The embryo proper, as well as separated extraembryonic tissues, of conceptuses collected about day 25 of pregnancy, were incubated with ${ }^{3}[H]$-estrone $\left(E_{1}\right)$ and ${ }^{3}[H]$-estradiol $\left(E_{2}\right)$. Steroids were recovered from media by solid-phase extraction and eluted separately as unconjugated and conjugated fractions. Profiles of free and sulfo-conjugated fractions were obtained by HPLC. Some differences and similarities were noted for the embryo proper as compared to the extraembryonic tissues. No reduction of $E_{1}$ to $E_{2}$ was noted for the embryo proper and allantois, but some was seen with the bilaminar Y-S wall. Less conversion of $E_{2}$ to $E_{1}$ occurred in the embryo proper than in the extraembryonic tissues. Profiles for hydrolyzed sulfates from incubation of the embryo proper were very similar for both substrates, mainly with $E_{1}$ present. Thus, low levels of reductase and high levels of oxido- activities were apparent for the $17 \beta$-hydroxysteroid dehydrogenase enzymes. Further evidence of an active role for the embryo proper was seen as minor, polar products, and an unknown compound eluting between $E_{2}$ and $E_{1}$. These findings show, for the first time, that the embryo proper can metabolize estrogens that are found in Y-S fluid - a function of potential significance at this stage in its development.
\end{abstract}

Reproduction (2009) 138 953-960

\section{Introduction}

The early conceptus in the mare synthesizes estrogens in increasing amounts from about day 12 of pregnancy (Heap et al. 1982, Zavy et al. 1984, Flood et al. 1987, Choi et al. 1997, Raeside et al. 2004). Although the full significance of this synthesis has not yet been established, it is presumed that estrogens play a role in the maintenance of pregnancy. A similar situation occurs in early pregnancy in the pig, where estrogen synthesis by the blastocyst is seen around days 10-12 of pregnancy (Perry et al. 1973), a time when $17 \beta$-estradiol $\left(E_{2}\right)$ has been shown to influence intrauterine migration of embryos (Pope et al. 1982) and uterine prostaglandin $F_{2 \alpha}$ secretion (Bazer \& Thatcher 1977). Estrogen formation by the early pig embryo is limited in duration with a transient expression of cytochrome P450 aromatase $\left(\mathrm{P}_{450} 0_{\text {arom }}\right)$ enzyme in the trophoblast, between days 10 and 12 (Conley et al. 1992, 1994). In contrast, the equine conceptus continues to synthesize estrogens, and in greater quantities, well beyond the initial apposition of trophoblast and uterine endometrium (Heap et al. 1982, Raeside et al. 2004). A role for the large amounts of estrogens present in yolk-sac (Y-S) fluid remains to be determined. More interest has been focused on their potential indirect effects on embryonic development - the participation of estrogens in an effective 'dialogue' between the conceptus (trophectoderm) and the uterine endometrium. However, it is also clear that the embryo proper is exposed to high concentrations of estrogens in the Y-S fluid over a protracted period in the early stages of equine pregnancy. The exposure is entirely through the vitelline stalk at first, but then becomes systemic as the vitelline blood circulation gets established. This raises the question of whether the estrogens could also have a direct effect on the embryo's development. Information on the amounts of estrogen that might be seen by the embryos in early stages in most mammalian species, other than the horse and pig, is extremely limited. Technical difficulties in obtaining material for measurement of steroids at the level of the conceptus, particularly in small laboratory animals, may be partly responsible.

There is now general consensus that metabolism of steroid hormones in target tissues may play a significant part in their overall action in many types of tissues; this is acknowledged by the introduction of the term intracrinology (Labrie et al. 2000). Many actions of $E_{2}$ are known to be due to its metabolites which act as local mediators in target tissues to effect changes not seen with 
$E_{2}$ in its unaltered state (Zhu \& Conney 1998). The antiproliferative and antiangiogenic properties of the 2-methoxy derivative of $E_{2}$ are examples of a product of local estrogen metabolism having profoundly different activities from those of the parent compound (D'Amato et al. 1994, Fotsis et al. 1994). Furthermore, the presence of specific enzymes in some target tissues can reduce the biological potency of $E_{2}$ by local conversion to estrone $\left(E_{1}\right)$, a much weaker estrogen in most instances, or by forming steroid conjugates such as sulfates and glucuronidates. Thus, knowledge of the metabolic fate of $E_{1}$ and $E_{2}$ in the embryo proper is a prerequisite for investigations on the possible direct action of estrogens on embryonic development.

In the present study we have examined the ability of the embryo proper to metabolize estrogens, using conceptuses (greater than day 20 of pregnancy) in which clear separation of the embryo proper from its extraembryonic membranes is feasible. Emphasis was placed on the metabolism of $\mathrm{E}_{1}$ because it is present at higher concentrations than $E_{2}$ in $Y-S$ fluid. Estrogen metabolism in the embryo proper was clearly demonstrated. Thus, the interest in the early secretion of estrogens by the Y-S wall is extended beyond its effects on the endometrium, to that of a direct role in early embryo development.

\section{Results}

The stage of development of an equine conceptus at day 25.5 of pregnancy, and of its contained embryo proper, is illustrated in Fig. 1. Note the development of the heart and the vascular system in the embryo proper. All specimens of the embryo proper used in this study were devoid of extraembryonic tissues.

\section{Estrogens in Y-S fluids}

The amounts of estrogens in Y-S fluid from the only conceptus that was recovered intact were 39.67, 7.74, 4.14 , and $2.01 \mathrm{ng} / \mathrm{ml}$ for $E_{1}$ sulfate $\left(E_{1} S\right), E_{1}, E_{2}$ sulfate $\left(E_{2} S\right)$, and $E_{2}$ respectively. Measurements were made by
RIA as previously described (Raeside et al. 2004). These values are consistent with those reported in that study and with those from RIA on Y-S fluid from mares at days 24-26 of pregnancy $(n=9)$, used in other aspects of our work $(39.67 \pm 19.13,8.20 \pm 3.75,4.27 \pm 0.77$, and $2.27 \pm 0.99$ S.D. $\mathrm{ng} / \mathrm{ml})$. $\mathrm{E}_{1}$ sulfate was clearly the predominant form at this stage in development.

\section{Conjugation of steroids}

The extent of conjugation of estrogens by the different components of the conceptus is given in Table 1. With the embryo proper, no difference was found in the extent of conjugation of the two substrates. Other tissues were included in the study only for qualitative comparison with metabolism by the embryo proper. All tissues showed a notable level of activity with the suggestion of less conjugation by bilaminar tissues with either substrate. More pertinently, the embryo proper was able to 1) form estrogen conjugates, and 2) do so to a degree matching that observed with extraembryonic tissues. The distribution of radioactive metabolites in the conjugate fraction after incubations with the embryo proper is given in Table 2, which shows that sulfo conjugation predominated. No comparable examination was made for the other tissues.

\section{HPLC profiles from estrogen metabolism}

The profiles illustrated are examples of the metabolism of $E_{1}$ or $E_{2}$ by the embryos proper. For the unconjugated steroids, distribution of radioactivity on chromatography for the metabolites formed by the embryo proper was clearly different for $E_{1}$ than that for $E_{2}$ (Fig. 2). The radioactivity from incubation of $E_{1}$ remained largely as unaltered substrate, with a minor amount occurring as a very polar product. No metabolism to $E_{2}$ was seen. Metabolism of $E_{2}$ was marked by a major conversion to $\mathrm{E}_{1}$ and to products considerably more polar than the substrate. Although the embryo proper had little or no ability to convert $E_{1}$ to $E_{2}$ under these conditions,
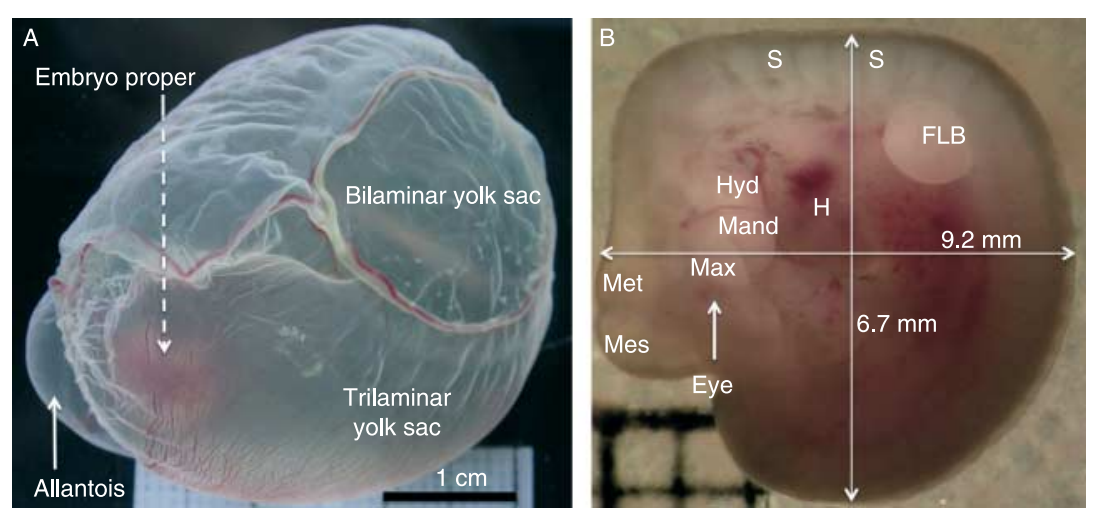

Figure 1 An equine embryo aged $25.5 \pm 0.5$ days. (A) Within the entire conceptus. Note particularly the vascularity of the splanchnic mesoderm of the trilaminar yolk-sac wall. (B) After stripping off the embryonic membranes. The future eye, heart $(H)$, somites (S), and fore-limb bud (FLB) are apparent but the hind-limb bud is obscured. The brain has differentiated into the mesencephalon (Mes) and metencephalon (Met). The maxillary process (Max) and the mandibular (Mand) and hyoid (Hyd) arches are prominent. Two $1 \mathrm{~mm}$ squares are shown in the bottom left of the image. 
Table 1 Percent radioactivity in the conjugate fractions from incubations of embryo proper and extraembryonic tissues with estrone or estradiol.

\begin{tabular}{lll}
\hline Tissue & ${ }^{3}[\mathbf{H}]$-Estrone & ${ }^{3}[\mathbf{H}]$-Estradiol \\
\hline Embryo proper & $19.3 \pm 5.5(n=6)^{\mathrm{a}}$ & $20.6(n=2)$ \\
Allantois & $22.1(n=2)$ & $20.1(n=2)$ \\
Bilaminar yolk-sac wall & $12.2 \pm 4.5(n=3)$ & $12.5(n=2)$ \\
Trilaminar yolk-sac wall & $19.1 \pm 4.8(n=3)$ & $16.2(n=2)$ \\
\hline
\end{tabular}

${ }^{a}$ Values are mean \pm s.D.; $n$, number of conceptuses.

it demonstrated nonetheless a considerable capacity for $\mathrm{E}_{2}$ metabolism even at such an early stage in development.

Other components of the equine conceptus were examined for comparison with estrogen metabolism in the embryo proper. For $E_{1}$ metabolism, the distribution pattern of radioactivity was almost indistinguishable between the embryo proper and the other tissues, with the exception of the bilaminar tissue (Fig. 3). As in our earlier study (Raeside et al. 2004), the bilaminar tissue exhibited a modest conversion of $\mathrm{E}_{1}$ to $\mathrm{E}_{2}$ (Fig. 3C). All showed small to trace amounts of polar products. $A$ small, unidentified peak between $E_{1}$ and $E_{2}$ had a retention time differing from that of $17 \alpha$-estradiol. The profiles of the embryo proper from two conceptuses (Figs $2 \mathrm{~A}$ and $3 \mathrm{~A}$ ) revealed a very high level of consistency.

Metabolism of $E_{2}$ was marked by a major conversion to $E_{1}$ and to products considerably more polar than the substrate (Fig. 4). All extraembryonic tissues showed a greater conversion of $E_{2}$ to $E_{1}$ than was noted for the embryo proper; this was especially so with the trilaminar tissues. A comparison of the profiles for $E_{2}$ metabolism by the embryo proper from two conceptuses shows a high level of agreement (Figs 2B and 4A). The repeatability in estrogen metabolism by the embryo proper is illustrated further by an approximation of the distribution of radioactivity from HPLC chromatography (Table 3). The totals of the unknown and polar products (28.3 and $27.5 \%$ ) formed from $\mathrm{E}_{1}$ by the two embryos proper were in close agreement; however, the amounts of the unknown compound $(\mathrm{X})$ produced were different.

HPLC profiles from solvolysis of the lesser amounts of radioactivity available in the conjugate fractions (about $20 \%$, see Table 1 ) were remarkably similar (Fig. 5), with only a trace of $E_{2}$ detected in the solvolysed material in

Table 2 Distribution of radioactivity (percent) ${ }^{\mathrm{a}}$ in conjugates formed by the embryo proper from estrone and estradiol.

\begin{tabular}{lccc}
\hline Substrate & Sulfate & Glucuronidate & Other \\
\hline$\left[{ }^{3} \mathrm{H}\right]-\mathrm{E}_{1}$ & 17.1 & 1.8 & 4.6 \\
{$\left[{ }^{3} \mathrm{H}\right]-\mathrm{E}_{2}$} & 12.6 & 2.5 & 7.3 \\
\hline
\end{tabular}

${ }^{\mathrm{a}}$ Mean values for embryos proper $(n=4)$ are expressed as percentage of total radioactivity recovered from duplicate incubations in two experiments for each substrate. each. Metabolism of $E_{1}$ resulted in $E_{1} S$ formation with only traces of other products. $E_{2}$ metabolism gave rise mainly to $E_{1} S$ and to several small peaks of polar products as sulfo conjugates (Fig. 5B). Only a small portion of $E_{2}$ as substrate had been metabolized to its sulfate form. The reductive action of $17 \beta$-hydroxysteroid dehydrogenase (17 $\beta-\mathrm{HSD})$ appeared extremely low for the sulfate form of $E_{1}$ (Fig. $5 A$ ) and absent for the unconjugated steroid (Figs $2 \mathrm{~A}$ and $3 \mathrm{~A}$ ). Similarly, $\mathrm{E}_{1}$ was evident on HPLC with the small amount of hydrolyzed material from the glucuronidate fractions, but no peaks for $E_{2}$ were seen from either estrogen as substrate (data not shown). The form of conjugation for the remaining non-hydrolyzed radioactive material has not yet been examined.

\section{Discussion}

These results are, to the best of our knowledge, the first to demonstrate estrogen metabolism by a mammalian embryo proper. The study was based on the premise that the embryo proper, in addition to the endometrium, might be a target for estrogen action. From our current findings and our earlier report (Raeside et al. 2004) on the large amounts of estrogens in Y-S fluid of equine conceptuses, it is inferred that estrogen production by the conceptus continues well beyond the phase of transuterine migrations that cease around day 16 of pregnancy. This differs markedly from the more transient production of estrogens in early pregnancy in the pig (Conley et al. 1992, 1994). A role for estrogens in the maternal recognition of pregnancy in the pig seems to have been established (Bazer \& Thatcher 1977) but the biological function of estrogen secretion by the equine conceptus remains to be defined. The continued presence of high levels of estrogens in Y-S fluid indicates that their action could extend beyond the maintenance

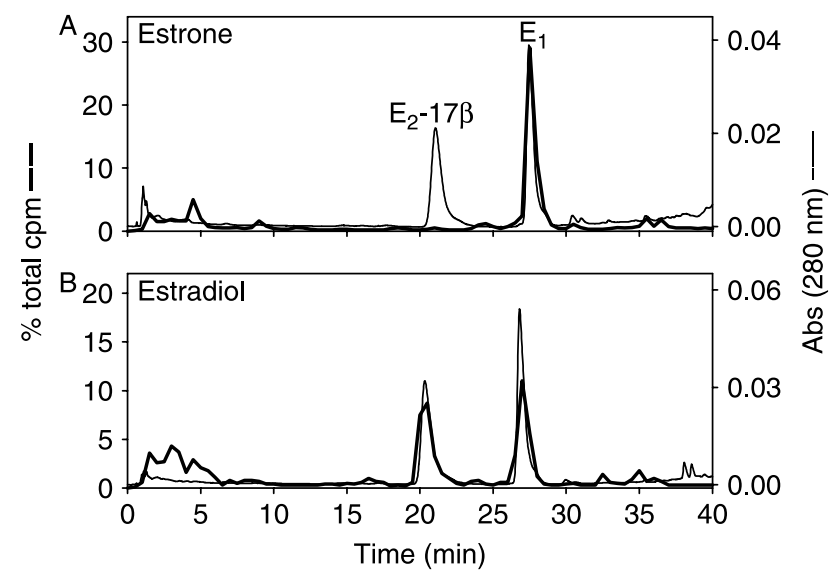

Figure 2 HPLC profiles of unconjugated metabolites in extracts of media from incubations of an embryo proper of a day $24.5 \pm 1.5$ conceptus with ${ }^{3}[\mathrm{H}]-\mathrm{E}_{1}(\mathrm{~A})$ or with ${ }^{3}[\mathrm{H}]-\mathrm{E}_{2}(\mathrm{~B})$. Estrogen reference standards are shown as a thin line. 


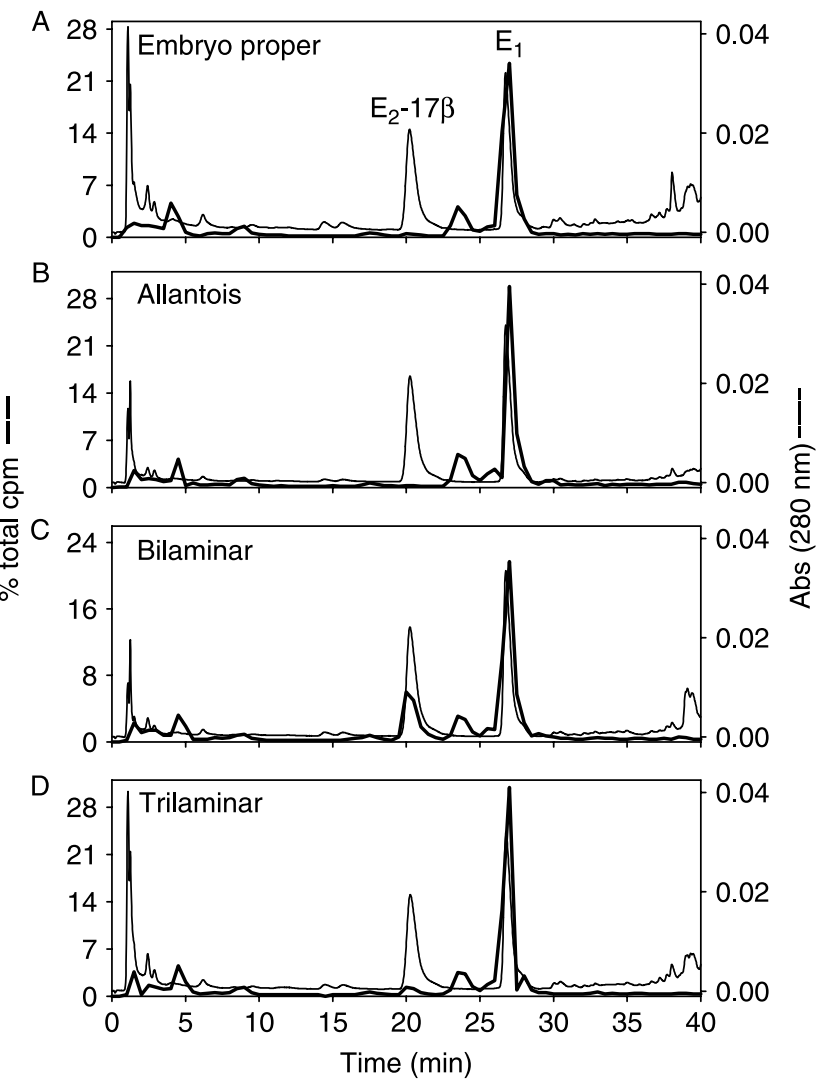

Figure $3 \mathrm{HPLC}$ profiles of unconjugated metabolites in extracts of media from incubations of the components of a day $25.5 \pm 0.5$ conceptus with ${ }^{3}[\mathrm{H}]-\mathrm{E}_{1}$. Estrogen reference standards are shown as a thin line.

of mobility of the conceptus within the uterus, as has been suggested (McDowell et al. 1988, Sharp et al. 1989). Nutritional support from the maternal endometrium may well be influenced by the conceptus-derived estrogens for an extensive period in early pregnancy of the mare in which placentation (in the sense of a stable, microvillous attachment of the non-invasive trophoblast of the allantochorion to the endometrium) is not established until about day 40 of gestation (Allen 2001).

The exposure of the embryo proper to high concentrations of estrogens over a prolonged period in early development (present results and Raeside et al. 2004) has not been reported for any other mammalian species, as far as we could determine. For more than 60 years, marsupials have provided a unique mammalian model to investigate the influence of estrogens on early gonadal development without the need for intrauterine surgery (Burns 1939, Fadem \& Tesoriero 1986). However, the possible action of estrogens during organogenesis before the early stages of formation of the gonads - has received little or no attention in either marsupials or eutherian mammals. Our study of the embryo proper involved specimens that were at a point well before sexual differentiation of the gonads in the horse (Merchant-Larios 1979, Knospe 1998).
The literature is extensive on the role of steroid hormones in sexual development in the lower vertebrates. Attention has been focused mainly on aberrations resulting from exposure of embryos to natural and synthetic estrogens in the environment, along with other endocrine disrupting agents (vom Saal et al. 1998, Safe et al. 2002). More relevant to our interest are the reports on the presence of steroids transferred naturally from the mother to the yolk in oviparous species. Although this was suspected more than 70 years ago (Altmann \& Hutt 1938), the first demonstration of naturally occurring yolk steroids was made many years later in birds (Schwabl 1993). There followed other similar studies in birds and in other oviparous vertebrates, as illustrated by the single citations chosen as examples for alligators (Conley et al. 1997), turtles (Bowden et al. 2000), lizards (Lovern \& Wade 2003), and fish (Khan et al. 1997). Again, the emphasis was on the possible effect of yolk steroids on sexual development. However, if yolk and embryo steroid contents change during incubation, when eggs have no further maternal contact, then an examination of the dynamics of yolk and embryo steroid content will yield insight into potential steroid production or metabolism by the embryo. In the green anole (Anolis carolinensis), for example, total yolk content of testosterone and $E_{2}$ generally declined over the course of incubation, indicating metabolism by the embryos during early stages of development; a later increase in testosterone, but not in $\mathrm{E}_{2}$, also gave evidence of steroid synthesis (Lovern \& Wade 2003).

The female reproductive endocrinology of elasmobranchs (sharks, skates, and rays) is considered by some to be the archetype for amniote vertebrates; and placentation in elasmobranchs approaches the eutherian condition (Callard et al. 1993). A study of the placental viviparous bonnethead shark (Sphyrna tiburo) allowed the investigation of both yolk and placental hormone transfers of steroid hormones in a single organism (Manire et al. 2004). In this species, nutrition is provided by yolk for the first half of embryonic development and by placental transfer for the second half. The pattern of yolk $E_{2}$ concentrations was most interesting. The dramatic decline in yolk $E_{2}$ levels between the post-ovulatory and the early pregnancy stages is consistent with the utilization of this hormone during embryonic development. A dramatic increase of $E_{2}$ after that, i.e. during the pre-implantation stage, would appear to be due to hormone production by the embryo concurrent with, or following, sex differentiation, especially given that maternal serum $E_{2}$ concentrations at the time are at baseline levels. No data on metabolism of $E_{2}$ were provided in any of these studies in spite of evidence of a decline in $E_{2}$ concentrations in the yolk and embryo proper.

The outstanding feature of estrogen metabolism in the equine embryo proper was the preferential expression of the oxidative form of $17 \beta-\mathrm{HSD}$ (type 2 ), converting $\mathrm{E}_{2}$ to $E_{1}$, has also been found in studies on fish embryos in both 

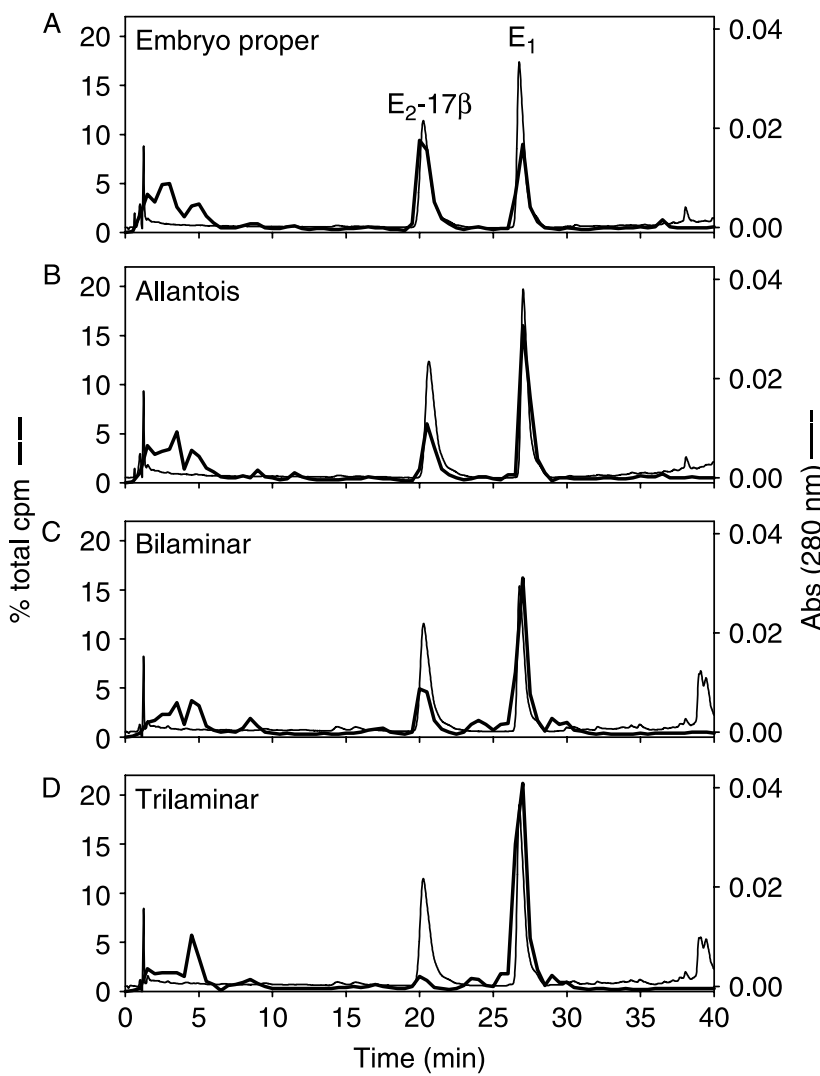

Figure $4 \mathrm{HPLC}$ profiles of unconjugated metabolites in extracts of media from incubations of the components of a day $25.0 \pm 1.0$ conceptus with ${ }^{3}[\mathrm{H}]-\mathrm{E}_{2}$. Estrogen reference standards are shown as a thin line.

Arctic charr (Khan et al. 1997) and rainbow trout (Petkam et al. 2002). This conversion was less pronounced than seen with the extraembryonic tissues, especially the trilaminar Y-S wall, but clearly demonstrated an ability of the embryo proper to regulate the degree of exposure to the more biologically active estrogen. Indeed, when $E_{1}$ was the substrate there was essentially no $E_{2}$ formed by the embryo proper in contrast to the amounts of $E_{2}$ noted for the bilaminar tissues. In all tissues, $E_{2}$ was further depleted by metabolism to highly polar products as yet not identified. They are most likely to be 6-oxygenated metabolites since their retention time on HPLC

Table 3 Distribution of radioactivity (percent) ${ }^{\mathrm{a}}$ for unconjugated steroids in HPLC profiles from metabolism by the embryo proper.

\begin{tabular}{llccrc}
\hline Profile & Substrate & $\mathbf{E}_{\mathbf{1}}$ & $\mathbf{E}_{\mathbf{2}}$ & $\mathbf{X}^{\mathrm{b}}$ & Polar \\
\hline 1 & {$\left[{ }^{3} \mathrm{H}\right]-\mathrm{E}_{1}$} & 49.1 & 1.1 & 3.7 & 24.6 \\
2 & {$\left[{ }^{3} \mathrm{H}\right]-\mathrm{E}_{1}$} & 49.5 & 1.6 & 10.4 & 17.1 \\
3 & {$\left[{ }^{3} \mathrm{H}\right]-\mathrm{E}_{2}$} & 21.8 & 23.1 & 1.8 & 27.0 \\
4 & {$\left[{ }^{3} \mathrm{H}\right]-\mathrm{E}_{2}$} & 16.6 & 24.1 & 1.5 & 30.2 \\
\hline
\end{tabular}

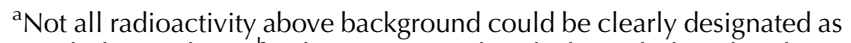
metabolic products. ${ }^{b} X$ denotes an unidentified metabolite eluted between $E_{2}$ and $E_{1}$. chromatography relates closely to products tentatively identified in our previous study with tissues of equine embryos from earlier stages (Raeside et al. 2004). The presence of these polar products was less noticeable when $E_{1}$ was the substrate; metabolism to the unidentified peak (not $17 \alpha-E_{2}$ ) between $E_{1}$ and $E_{2}$ may have been partly responsible. Lastly, evidence of enzyme activity leading to conjugation of estrogens, as steroid sulfates, glucuronidates, and other forms (perhaps with glutathione) by the embryo proper has a parallel in the formation of similar products by fish embryos in Arctic charr (Khan et al. 1997), and in rainbow (Petkam et al. 2002), and steelhead (Yeoh et al. 1996) trout. A marked conversion of $E_{2}$ to $E_{1}$, followed by preferential metabolism of $E_{1}$ to its conjugated forms provides protection from exposure to potentially mutagenic products derived from $E_{2}$. The qualitative support for this view is considered substantial in the consistency of the metabolic profiles; and despite the severe limitations in obtaining sufficient material for replication of experiments of this nature, there are reasonable grounds for concluding that the embryo proper is actively engaged in estrogen metabolism at this stage of development.

Whereas it is clear that the embryo proper is an active participant in establishing and regulating its endocrine environment with respect to endogenous estrogens, the biological significance and possible activity of some of the metabolites formed remains unknown. The putative 6-oxygenated metabolites produced by the equine embryo proper, from both $E_{2}$ and $E_{1}$, have been referred to as 'impeded' estrogens from their repression of uterine growth (Huggins \& Jensen 1955). A possible role for the unknown compound formed from $E_{1}$ by the embryo proper, and by all of the extraembryonic tissues, represents another example of metabolism. However, quantitatively more important is the metabolism of $E_{2}$ to

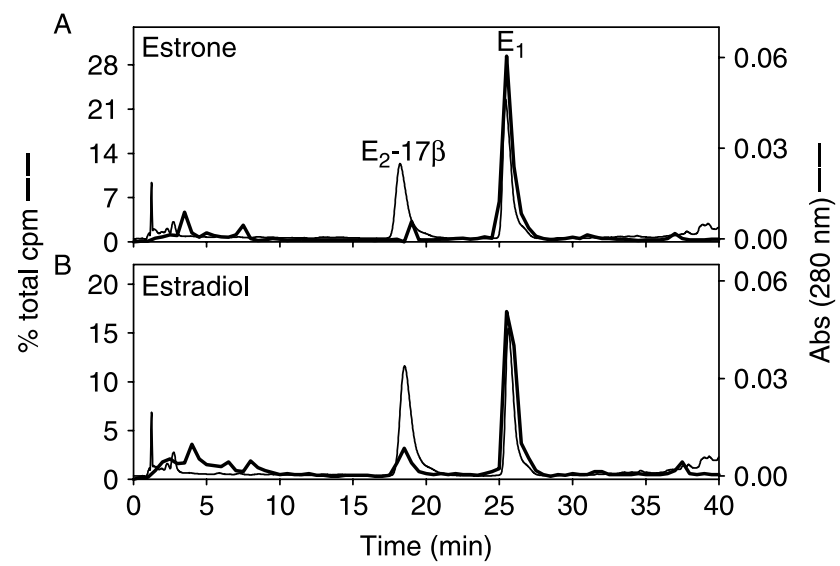

Figure 5 HPLC profiles of sulfo-conjugated metabolites in extracts of media from incubations of an embryo proper of a day $24.5 \pm 1.5$ conceptus with ${ }^{3}[H]-E_{1}(A)$ and with ${ }^{3}[H]-E_{2}(B)$. Estrogen reference standards are shown as a thin line. 
$E_{1}$ and $E_{1} S$. While $E_{2}$ itself might act in the embryo proper in its well-known role as an angiogenic agent (note the vascular development in Fig. 1) the presence of greater concentrations of $E_{1}$ and $E_{1} S$ could also contribute in a significant manner. Both $E_{1}$ and estriol are designated as 'weak' estrogens in genomic actions but have recently been shown to be strong estrogens in nongenomic signalling pathways and in evoking functional responses in pituitary cells (Watson et al. 2008). This may be true for $E_{1}$ in vascular tissues also (Rauschemberger et al. 2008). The dominant presence of $\mathrm{E}_{1} \mathrm{~S}$ in $\mathrm{Y}-\mathrm{S}$ fluid and its formation by the embryo proper raises questions about its relevance to early embryo development. Does it represent an endpoint in metabolism of $E_{2}$, to an inactive product, or does it serve as a source for later retrieval of an active estrogen by means of an estrogen sulfatase? A recent report provides an alternative answer based on a demonstration of a receptor-independent effect of physiological levels of $\mathrm{E}_{1} \mathrm{~S}$ (Kakusaka et al. 2009). Lastly, the presence of other forms of conjugation, accounting for about one-third of conjugates, suggests further activity on the part of the embryo proper in regulating its exposure to biologically active estrogens.

The absence of information on the occurrence, type, and location of estrogen receptors (ESR) at this stage of development places limits on interpretation of the biological importance of local enzyme activity on steroids. At a slightly earlier stage in development of the equine conceptus, day 10-16, no ESR1 could be detected; however, it was shown that ESR2 gene expression begins on or around day 10 of gestation, with translation to protein by day 14 (Rambags et al. 2008). Immunoreactive protein was localized to the extraembryonic trophectoderm; no evidence for either ESR was recorded for the embryonic disc or embryo proper. Whereas further studies along these lines should be informative, nongenomic actions of the several products of estrogen metabolism by the embryo proper might also have to be considered.

In conclusion, we have shown that the equine embryo proper displays a remarkable ability to exercise some control over its endocrine environment with respect to the high levels of estrogens in the surrounding Y-S fluid. It remains to be determined if species with a similar placental type (Wooding et al. 2003) have the same metabolic capabilities for estrogen metabolism displayed by the equine embryo proper. A study of the direct action of estrogens on the embryo proper, however, is never likely to be done with the horse. While our findings of estrogen metabolism are probably the first of this nature in a eutherian species, they suggest that studies on direct effects of estrogens (e.g. angiogenesis) in the early embryo proper in other species may lead to a more complete appreciation of their role in early development.

\section{Materials and Methods}

\section{Chemicals and reagents}

Nonradioactive steroids were purchased from Steraloids Inc (Newport, RI, USA). The radioactive steroids (NEN) obtained from Perkin-Elmer (Shelton, CT, USA) were $\left[2,4,6,7-{ }^{3} \mathrm{H}\right]-\mathrm{E}_{2}$ $(71.0 \mathrm{Ci} / \mathrm{mmol})$ and $\left[2,4,6,7{ }_{-}^{3} \mathrm{H}\right]-\mathrm{E}_{1}(74.1 \mathrm{Ci} / \mathrm{mmol})$. Solvents from Caledon Laboratories, Ltd (Georgetown, ON, Canada) were glass-distilled and reagent grade; and acetonitrile (HPLC grade 190) was used for HPLC. Medium 199 and supplements were supplied by Sigma. All other chemicals were analytical grade from Fisher Scientific (Toronto, ON, Canada).

\section{Collection of conceptuses}

Standardbred and thoroughbred mares from the research herd at the University of Guelph were used to recover seven conceptuses at days 24-25 under conditions approved by the University Animal Care Committee. The timing of ovulation was monitored by transrectal ultrasonography either daily $(n=3)$ or at intervals of $2(n=1)$ or 3 days $(n=3)$ and ovulation was deemed to have occurred on day 0 , midway between examinations showing an intact follicle and a corpus luteum. Thus, ages of conceptuses were subject to an error of $\pm 0.5-1.5$ days. Conceptuses were collected from mares by transcervical uterine lavage, with Dulbecco's PBS, pH 7.4, using a technique based on one previously described (Raeside et al. 2004). The mares were sedated with xylazine hydrochloride (Rompun; BAY-VET, Etobicoke, ON, Canada), administered i.v., usually $0.3 \mathrm{mg} / \mathrm{kg}$ body weight. The flush fluid $(1000 \mathrm{ml}$, repeated as necessary) was infused by gravity flow and drained into a beaker to recover the conceptus. Y-S fluid was obtained from only one of the seven conceptuses used.

\section{Dissection to recover the embryo proper}

Under a dissecting microscope, the embryo proper in PBS was dissected free of its extraembryonic membranes (Y-S, allantois and amnion) using ophthalmic scissors and forceps.

\section{Tissue preparation and incubation}

After separation, the embryo proper was washed, minced, and incubated (20-30 mg) with the radiolabeled estrogens. Duplicate incubations were performed (except for single incubations in two instances) with $E_{2}$ or $E_{1}$ as substrate. The $Y-S$ wall was divided into bilaminar (trophectoderm and endoderm) and trilaminar (trophectoderm, mesoderm, and endoderm) components by dissection, and these were incubated separately (10-20 and 35-70 mg of tissue, respectively, in duplicate). Allantoic tissues (10-20 mg, in duplicate) were also incubated but the amnion, which was sparse, avascular, and shredded by the dissection, was not. All tissues were washed with PBS and dispensed into small flasks containing $2 \mathrm{ml}$ Medium 199 to which either $\left[{ }^{3} \mathrm{H}\right]-\mathrm{E}_{1}$ or $\left[{ }^{3} \mathrm{H}\right]-\mathrm{E}_{2}\left(1 \times 10^{6}\right.$ c.p.m. $)$ was added for incubation in a shaking water-bath at $37{ }^{\circ} \mathrm{C}$ under $5 \% \mathrm{CO}_{2}$ in air for $2 \mathrm{~h}$. 


\section{Analytical procedures}

Steroids in the media were recovered by solid-phase extraction as previously described by Raeside et al. (2004). Briefly, medium from the incubation was diluted with water to a volume of $5 \mathrm{ml}$ for solid-phase extraction (Waters C18 Sep-Pak column, Canada Waters Ltd, Mississauga, ON, Canada). Unconjugated and conjugated steroids were eluted from the primed columns with $5 \mathrm{ml}$ of diethyl ether and $5 \mathrm{ml}$ of methanol, successively. The ether and methanol eluates were evaporated, separately, under nitrogen at $<45^{\circ} \mathrm{C}$; the dried ether residue (unconjugated fraction) was used for HPLC. The conjugated material underwent two hydrolytic steps, in series, to yield a 'sulfate' and a 'glucuronidate' fraction obtained in each case as free steroids from Sep-Pak columns (Raeside et al. 1999). The amounts of radioactive material recovered from each incubation, each hydrolysis step and in each Sep-Pak fraction were determined by liquid scintillation counting in $4 \mathrm{ml}$ of Ecolite cocktail (MP Biochemicals, Santa Ana, CA, USA). In addition, an indirect assessment of metabolism involving loss of the tritium-label at carbons 2, 4, 6, and/or 7 was made by measuring the amount of radioactivity in the initial (flow-through) and the following (water-wash) fraction from the solid-phase extraction. These aqueous fractions were deemed to reflect the formation of $\left[{ }^{3} \mathrm{H}\right]_{2} \mathrm{O}$ from oxygenation at the tritium-labeled carbon sites of the estrogen molecule (Raeside et al. 2004).

Unconjugated and hydrolyzed steroids in the fractions derived serially from Sep-Pak columns were examined by HPLC. Profiles of steroid metabolic products were generated using a binary solvent gradient (Waters \# 8) of acetonitrile:water (from 28:72 to 90:10, over $40 \mathrm{~min}$ ) on a Waters HPLC C1 8 column and system (Waters Corp., Milford, MA, USA) at a flow-rate of $1.0 \mathrm{ml} / \mathrm{min}$ and absorbance monitored at $280 \mathrm{~nm}$. Fractions were collected at $0.5 \mathrm{~min}$ intervals. The total radioactivity in the detected peaks was used for quantitative comparisons of the products formed (as \% of total radioactivity). Identification of the radiolabeled metabolites was based on their co-elution with authentic reference steroids run as internal standards or in separate chromatograms.

\section{Statistical analysis}

Results are expressed as means \pm s.D. Data were analyzed by Student's $t$-test. Differences were considered significant when $P<0.05$.

\section{Declaration of interest}

The authors declare that there is no conflict of interest that could be perceived as prejudicing the impartiality of the research reported.

\section{Funding}

This work was supported by grants from the Natural Sciences and Engineering Research Council of Canada, the GraysonJockey Club Research Foundation, Equine Guelph, and by the Ontario Ministry of Agriculture, Food and Rural Affairs.

\section{References}

Allen WR 2001 Fetomaternal interactions and influences during equine pregnancy. Reproduction 121 513-527.

Altmann M \& Hutt FB 1938 The influence of estrogens in egg yolk upon avian blood calcium. Endocrinology 23 793-799.

Bazer FW \& Thatcher WW 1977 Theory of maternal recognition of pregnancy in swine based on estrogen controlled endocrine versus exocrine secretion of prostaglandin $\mathrm{F}_{2 \alpha}$ by the uterine endometrium. Prostaglandins 14 397-400.

Bowden RM, Ewert MA \& Nelson CE 2000 Environmental sex determination in a reptile varies seasonally and with yolk hormones. Proceedings of the Royal Society of London Series B 267 1745-1749.

Burns RK Jr 1939 Sex differentiation during the early pouch stages of the opossum and a comparison of the anatomical changes induced by the male and female sex hormones. Journal of Morphology 65 497-547.

Callard IP, Fileti LA \& Koob TJ 1993 Ovarian steroid synthesis and the hormonal control of the elasmobranch reproductive tract. Environmental Biology of Fishes 38 175-185.

Choi SJ, Anderson GB \& Roser JF 1997 Production of free estrogens and estrogen conjugates by the preimplantation equine embryo. Theriogenology 47 457-466.

Conley AJ, Christensen RK, Ford SP, Geisert RD \& Mason JI 1992 Steroidogenic expression in porcine conceptuses during and after elongation. Endocrinology 131 896-902.

Conley AJ, Christensen KK, Ford SP \& Christensen RK 1994 Immunocytochemical localization of cytochromes P450, 17 $\alpha$-hydroxylase and aromatase in embryonic cell layers of elongating porcine blastocysts. Endocrinology 135 2248-2254.

Conley AJ, Elf P, Corbin CJ, Dubowsky S, Fivizzani A \& Lang JW 1997 Yolk steroids decline during sexual differentiation in the alligator. General and Comparative Endocrinology 107 191-200.

D'Amato RJ, Lin CM, Flynn E, Folkman J \& Hamel E 1994 2-Methoxyestradiol, an endogenous mammalian metabolite, inhibits tubulin polymerization by interacting at the colchicine site. PNAS 91 3964-3968.

Fadem BH \& Tesoriero JV 1986 Inhibition of testicular development and feminization of the female genitalia by neonatal estrogen treatment in a marsupial. Biology of Reproduction 34 771-776.

Flood PF, Betteridge KJ \& Irvine DS 1987 Oestrogens and androgens in blastocoelic fluid and cultures of cells from equine conceptuses of 10-22 days gestation. Journal of Reproduction and Fertility $\mathbf{2 7}$ 414-420.

Fotsis T, Zhang Y, Pepper MS, Adlercreutz H, Montesano R, Nawroth PP \& Schweigerer L 1994 The endogenous oestrogen metabolite 2-methoxyoestradiol inhibits angiogenesis and suppresses tumour growth. Nature 368 237-239.

Heap RB, Hamon M \& Allen WR 1982 Studies on oestrogen synthesis by the preimplantation equine conceptus. Journal of Reproduction and Fertility 32 343-352.

Huggins C \& Jensen EV 1955 The depression of estrone-induced uterine growth by phenolic estrogens with oxygenated functions at positions 6 or 16: the impeded estrogens. Journal of Experimental Medicine 102 335-346.

Kakusaka S, Asayama M, Kaihara A, Sasano T, Suzuki T, Kurokawa J \& Furukawa T 2009 A receptor-independent effect of estrone sulfate on the HERG channel. Journal of Pharmacological Sciences 109 152-156.

Khan MN, Renaud RL \& Leatherland JF 1997 Metabolism of estrogens and androgens by embryonic tissues of Arctic charr, Salvelinus alpinus. General and Comparative Endocrinology 107 118-127.

Knospe C 1998 Zur Entwicklung des Pferdehodens. Anatomia, Histologia, Embryologia 27 219-222.

Labrie F, Luue-The V, Lin SX, Simard J, Labrie C, El-Alfy M, Pelletier G \& Belanger A 2000 Intracrinology: role of the family of $17 \beta$-hydroxysteroid dehydrogenases in human physiology and disease. Journal of Molecular Endocrinology 25 1-16.

Lovern MB \& Wade J 2003 Sex steroids in green anoles (Anolis carolinensis): uncoupled maternal plasma and yolking follicle concentrations, potential embryonic steroidogenesis, and evolutionary implications. General and Comparative Endocrinology 134 109-115. 
Manire CA, Rasmussen LEL, Gelsleichter J \& Hess DL 2004 Maternal serum and yolk hormone concentrations in the placental viviparous bonnethead shark, Sphyrna tiburo. General and Comparative Endocrinology $136241-247$.

McDowell KJ, Sharp DC, Grubaugh W, Thatcher WW \& Wilcox CJ 1988 Restricted conceptus mobility results in failure of pregnancy maintenance in mares. Biology of Reproduction 39 340-348.

Merchant-Larios H 1979 Ultrastructural events in horse gonadal morphogenesis. Journal of Reproduction and Fertility 27 479-485.

Perry JS, Heap RB \& Amoroso EC 1973 Early pregnancy in the pig. Nature 245 175-188.

Petkam R, Renaud RL, Freitas AMMS, Canario AVM \& Leatherland JF 2002 In vitro metabolism of progesterone, androgens and estrogens by rainbow trout embryos. Fish Physiology and Biochemistry 27 117-128.

Pope WF, Maurer RR \& Stormshak F 1982 Intrauterine migration of the porcine embryo: influence of estradiol-17 $\beta$ and histamine. Biology of Reproduction 27 575-579.

Raeside JI, Christie HL \& Renaud RL 1999 Androgen and estrogen metabolism in the reproductive tract and the accessory sex glands of the domestic boar (Sus scrofa). Biology of Reproduction 61 1242-1248.

Raeside JI, Christie HL, Renaud RL, Waelchli RO \& Betteridge KJ 2004 Estrogen metabolism in the equine conceptus and endometrium during early pregnancy in relation to estrogen concentrations in yolk-sac fluid. Biology of Reproduction 71 1121-1127.

Rambags BP, van Tol HT, van den Eng MM, Colenbrander B \& Stout TA 2008 Expression of progesterone and oestrogen receptors by early intrauterine conceptuses. Theriogenology $69366-375$.

Rauschemberger MB, Sellés J \& Massheimer V 2008 The direct action of estrone on vascular tissue involves genomic and non-genomic actions. Life Sciences 82 115-123.

vom Saal FS, Cooke PS, Buchanan DL, Palanza P, Thayer KA, Nagel SC, Parmigiani S \& Welshons WV 1998 A physiologically based approach to the study of bisphenol A and other estrogenic chemicals on the size of reproductive organs, daily sperm production, and behavior. Toxicology and Industrial Health 14 239-260.

Safe SH, Pallaroni L, Yoon K, Gaido K, Ross S \& McDonnell D 2002 Problems for risk assessment of endocrine-active estrogenic compounds. Review. Environmental Health Perspectives 110 925-929.

Schwabl H 1993 Yolk is a source of maternal testosterone for developing birds. PNAS 90 11446-11450.

Sharp DC, McDowell KJ, Weithenauer J \& Thatcher WW 1989 The continuum of events leading to maternal recognition of pregnancy in mares. Journal of Reproduction and Fertility 37 101-107.

Watson CS, Jeng YJ \& Kochukov MY 2008 Nongenomic actions of estradiol compared with estrone and estriol in pituitary tumor cell signaling and proliferation. FASEB Journal 22 3328-3336.

Wooding FBP, Ozturk M, Skidmore JA \& Allen WR 2003 Developmental changes in localization of steroid synthesis enzymes in camelid placenta. Reproduction 126 239-247.

Yeoh C-G, Schreck CB, Fitzpatrick MS \& Feist GW 1996 In vivo steroid metabolism in embryonic and newly hatched steelhead trout (Oncorhynchus mykiss). General and Comparative Endocrinology 102 197-209.

Zavy MT, Vernon MW, Sharp DC \& Bazer FW 1984 Endocrine aspects of early pregnancy in pony mares. Endocrinology 115 214-219.

Zhu BT \& Conney AH 1998 Functional role of estrogen metabolism in target cells: review and perspectives. Carcinogenesis 19 1-27.

Received 8 July 2009

First decision 29 July 2009

Accepted 25 August 2009 